\title{
The rupture life prediction in cold dwell fatigue of Ti-6Al-4V based on the creep deformation
}

\author{
Yutaro Ota ${ }^{1}$, Tomomichi Ozaki ${ }^{1}$, Keiji Kubushiro.O ${ }^{2}$ \\ 1 IHI Technology platform center, 1,Shin-nakaharacho, Isogo-ku, Yokohama, Japan \\ 2 IHI Asia Pacific Thailand, 11th and 12th Floor, Ramaland Building, 952 Rama IV Road, Suriyawongse, \\ Bangrak, Bangkok 10500, Thailand
}

\begin{abstract}
$\underline{\text { Abstract }}$
Titanium alloys have been found that the fatigue strength of Ti alloys decreases due to cold dwell fatigue $(\mathrm{CDF})$ at room temperature. $\mathrm{Ti}$ and $\mathrm{Ti}$ alloys generate creep deformation at room temperature $(\mathrm{T} / \mathrm{Tm}=0.15)$. Thus, it is considered that creep affects the reduction in fatigue life in CDF tests. This research intends to clarify the effects of long time dwell under tensile stress and rupture life prediction from the view of creep deformation in CDF characteristics of Ti-6Al-4V. Rupture cycle decreased with increase of dwell time. Additionally, lower limit of rupture life ratio "NCDF/NLCF" was defined from rupture in creep test if it was assumed that creep test was extremely long time dwell CDF test. When strain change in whole dwell time was extracted in CDF tests, strain change was like creep curves and minimum creep rate changed depending on dwell time. Minimum creep rate was calculated by the formula based on experimental results, and then rupture time was calculated by Monkman-grant relationship. All of rupture cycle predictions were in factor of 2. Therefore, rupture cycle and time can be calculated if dwell time is known in CDF tests.
\end{abstract}

\section{Introduction}

Titanium alloys are used for a wide variety of members and parts because they have high specific strength as well as high corrosion resistance. However, it has been found that the fatigue strength of Ti alloys decreases due to cold dwell fatigue (CDF) at room temperature, and there have been reports on cases of damage due to decrease fatigue life [1-12].

Generally, most of metals are deformed by creep phenomenon at higher temperature (T/Tm $>0.3$, where $\mathrm{Tm}$ is melting point). In contrast, $\mathrm{Ti}$ and $\mathrm{Ti}$ alloys generate creep deformation at room temperature $(\mathrm{T} / \mathrm{Tm}=0.15)$ $[13,14]$. Ti and $\mathrm{Ti}$ alloys generate creep deformations when stress exceeds a certain level, even at room temperature [15]. Thus, it is considered that creep affects the reduction in fatigue life in CDF tests.

When considering CDF tests, the likelihood of creep generation rises with the increase in dwell time under stress; therefore, the rate of fatigue life reduction also goes up with increases in dwell time under stress. However, most of the existing reports discuss the CDF test results with the dwell time under stress in a range of up to $300 \mathrm{~s}$, and there have been very few reports dealing with the effects of long dwell time under stress on the reduction of fatigue life.

Thus, this research intends to clarify the effects of long time dwell under tensile stress and rupture life prediction from the view of creep deformation in CDF characteristics of Ti-6Al-4V.

\section{Material and experiments}

The material under test was a Ti-6Al-4V billet whose composition is shown in table 1. A billet with a height of $190 \mathrm{~mm}$ was forged at $850^{\circ} \mathrm{C}$ to process it into a plate with a thickness of $30 \mathrm{~mm}$. The heat treatments were furnace-cooled (FC) annealing at $950^{\circ} \mathrm{C}$ for 2 hours and aging treatment at $700^{\circ} \mathrm{C}$ for 2 hours. The tensile test pieces had a diameter of $6 \mathrm{~mm}$ and a gauge length of $30 \mathrm{~mm}$ and the tensile tests were performed at room temperature with a strain rate of 3.3 $\times 10-3 \mathrm{~s}-1$. The fatigue test pieces had a diameter of $6 \mathrm{~mm}$ and a gauge length of $40 \mathrm{~mm}$. The LCF test and CDF test with the introduction of dwell time under stress were conducted at room temperature in air. These fatigue tests were carried out under the following conditions: $\mathrm{R}=0$, a triangular waveform for the LCF test and a tensile-stress-retained trapezoid waveform for the CDF test; stress amplitude of $876 \mathrm{MPa}$; stress application and release durations of 2 s respectively; and dwell time under stress of $0 \mathrm{~s}$ to $7,200 \mathrm{~s}$. Creep tests at room temperature with test pieces having a diameter of $6 \mathrm{~mm}$ and a gauge length of $30 \mathrm{~mm}$, and stress of $876 \mathrm{MPa}$. 


\begin{tabular}{|l|l|l|l|l|l|l|}
\hline $\mathrm{Ti}$ & $\mathrm{Al}$ & $\mathrm{V}$ & $\mathrm{Fe}$ & $\mathrm{O}$ & $\mathrm{N}$ & $\mathrm{C}$ \\
\hline Bal. & 6.40 & 4.12 & 0.16 & 0.17 & 0.025 & 0.028 \\
\hline
\end{tabular}

\section{Results \& Discussion}

After the heat treatment, microstructure was consisted with most of equiaxed $\alpha$ grains whose size was about $10 \mu \mathrm{m} . \beta$ volume fraction was about $3 \%$.

From tensile test results, $0.2 \%$ yield strength was $950 \mathrm{MPa}$ and fracture elongation was $14.0 \%$. It means that maximum stress in fatigue test and creep test was corresponded to $0.922 \sigma 0.2$.

In the fatigue tests, fracture cycle life of LCF (without dwell) test was 10,663 cycles and that in $120 \mathrm{~s}$ dwell test decreased to 999 cycles. Furthermore, that in 1800s and 7200s dwell tests was 256 and 236 cycles respectively. From the above, fracture cycle life decreased with increase of dwell time to 7,200s. Additionally, fracture elongation increase remarkably in CDF tests with increasing in dwell time, compared to LCF test. Fracture elongation in LCF was only $2.8 \%$, in contrast, that was $17.5 \%, 18.1 \%$, and $18.8 \%$ in $120 \mathrm{~s}, 1800 \mathrm{~s}$, and $7200 \mathrm{~s}$ dwell test respectively. As fracture surface morphology some striations were observed at fracture surfaces of LCF test piece, but almost dimples were observed at fracture surfaces of CDF test pieces. In Figure 1, fracture surface after 120s dwell CDF test as an example is shown due to same morphology regardless of dwell time.

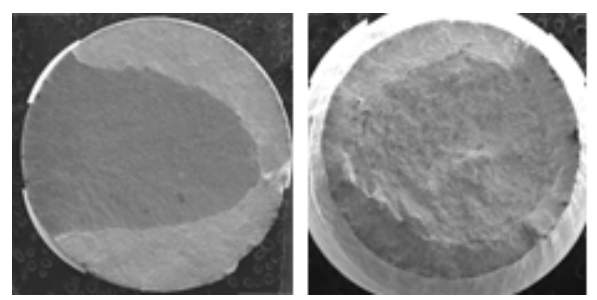

Figure 1: fracture surfaces of the test pieces after (a) LCF and (b) 120s dwell CDF tests.

In the creep test at $876 \mathrm{MPa}$ which was same as maximum stress of CDF tests, rupture time was $858.8 \mathrm{~h}$ and the rupture elongation was $14.7 \%$. Rupture in creep test can be defined as 1 cycle rupture in CDF tests. Minimum dwell fatigue life debit "NCDF/NLCF" was 0.022 in 7200 s dwell test in this study to here. According to creep test results, however, it is suggested that dwell fatigue life debit has the lower limit, which is about 9.4x10-5. Although it has been unknown whether there is a lower limit of life debit or not, it was shown in this study.

When strain change in whole dwell time was extracted, strain change was like creep curves although loading-unloading were repeated over 100 times in CDF tests. Figure 2 shows the creep curve and that accumulation of strain in holding versus whole dwell loading time. In the strain range from $0 \%$ to about $4 \%$, almost same curves were drawn regardless of dwell time. In over $4 \%$ strain, trends of curves were different depending on dwell time to include creep test. In straight region like steady state creep, the inclinations become smaller as dwell time is longer. This means that minimum creep rate decrease with increase of depends dwell time.

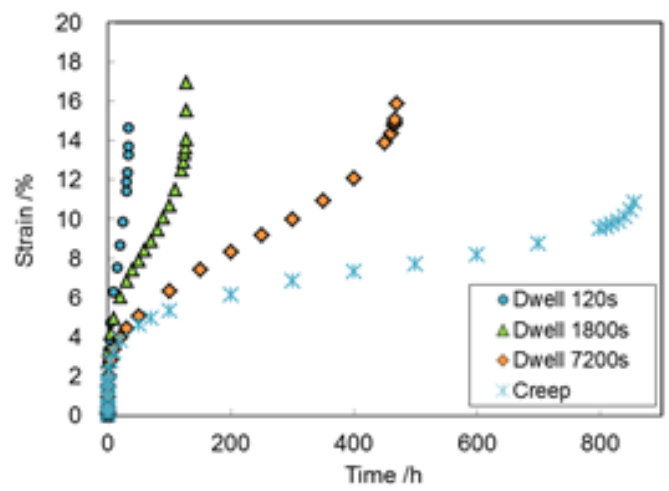

Figure 2: The creep strain changes in creep test and CDF test during dwell time under stress. 
Generally, if stress and temperature are constant in creep, minimum creep rate is also constant [16]. However, minimum creep rate in CDF creep curve depends on only dwell time regardless of constant stress and temperature. Figure 3 shows the minimum creep rate versus dwell time (creep test is defined as extremely long dwell) and it is confirmed that there is a relationship expressed a power low curve. Moreover, the result to multiply minimum creep rates and whole dwell time in the tests was constant, which is Monkman-Garant relationship. This means that rupture life can be predicted if minimum creep rate is expressed by a formula. Therefore, formulation of minimum creep rate with dwell time leads to prediction of rupture time life in CDF.

Minimum creep rate was calculated by the formula based on experimental results (Figure 3), and then rupture time was calculated by Monkman-grant relationship. Rupture cycle converted from predicted rupture time and experimental rupture cycle were plotted in fig 4. All of results were in factor of 2 . Therefore, rupture cycle and time can be calculated if dwell time is known in CDF tests.

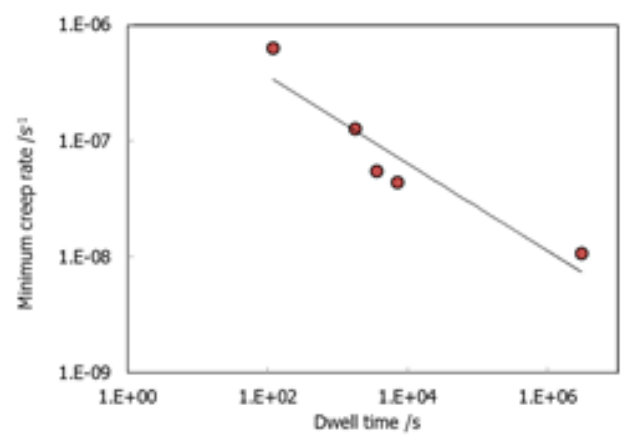

Figure 3: Minimum creep rate vs dwell time in CDF test (rupture time in creep test)

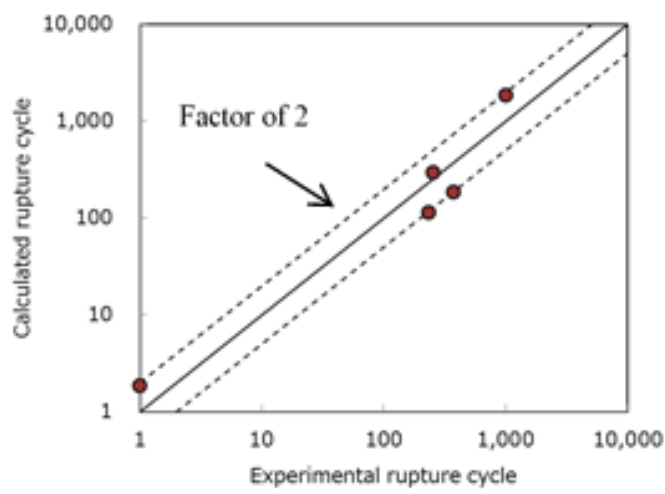

Figure 4: The relationship between experimental and calculated rupture cycle.

\section{Conclusion}

In this study, the effects of long term dwell in CDF tests were discussed. It was confirmed that there was a lower limit of fracture cycle life debit because rupture in creep test was defined as 1cycle of CDF. In CDF tests, accumulation of strain in whole dwell time showed creep curves and their minimum creep rate was depended on dwell time. The rupture life can be predicted within factor of 2 if dwell time is known in CDF tests.

\section{Reference}

[1] M. R. Bache, Int. J Fatigue 25 (2003) 1079-1087.

[2] M. R. Bache, M. Cope, H.M. Davies, W.J. Evans, G, Int. J Fatigue 19 (1997) S83-S88.

[3] J. QIU, Y. MA, J. LEI, Y. LIU, A. HUANG, D. RUGG, R. YANG, Metal \& Mater. Trans. A 45 (2014) 6076-6087.

[4] L. Toubal, P. Bocher, A. Moreau, Int. J Fatigue 31 (2009) 601-605.

[5] L. Yang, J. Liu, J. Tan, Z. Chen, Q. Wang, R. Yang, J Mater. Sci. Tech. 30 (2014) 706-709.

[6] M.L. Thomsen, D.W. Hoeppner, Int. J Fatigue 20 (1998) 309-317.

[7] J. Peng, C.Y. Zhou, Q. Dai, X.H. He, Mater. and Design 71 (2015) 1-16. 
[8] V. Chandravanshi, K. Prasad, V. Singh, A. Bhattacharjee, V. Kumar, Int. J Fatigue 91 (2016) 100-109.

[9] Z. Zheng, D.S. Balint, F. P.E. Dunne, Journal of the Mechanics and Physics of Solids 107 (2017) 185203.

[10] I. Bantounas, T.C. Lindley, D. Rugg, D. Dye, Acta Materialia 55 (2007) 5655-5665.

[11] S. Hemery, P. Villechaise, Metal \& Mater. Trans. A 697 (2017) 177-183.

[12] F. Wang, W. Cui, Mater. Sci. and Eng. A 642 (2015) 136-141.

[13] H. Adenstebt, Metal Progress 56 (1949) 658-660.

[14] B.C. Odegard, A.W. Thompson, Metal Trans. A 5 (1974) 1207-1213.

[15] Kameyama, T. Matsunaga, S. Ueda, E. Sato, K. Kuribayashi, Journal of Japan Institute of Light Metals 60 (2010) 111-116.

[16] e.g. ASTM DS 11 S1(1970). 